\title{
A justiça restaurativa como um novo olhar sobre Justiça Juvenil Brasileira
}

Restorative justice as a new look at Brazilian Juvenile Justice

Selma Pereira de Santana*

Sóstenes Jesus dos Santos Macêdo ${ }^{* *}$

\begin{abstract}
RESUMO: Discute brevemente a Justiça Restaurativa como uma maneira de pensar e fazer a Justiça, reavendo o papel das partes envolvidas no conflito. Ante o movimento restaurativo, analisar-se-ão algumas características das suas principais práticas restaurativas como transformadoras na busca pela resolução pacífica dos conflitos. Por conseguinte, se cuidará sobre o sistema de Justiça Juvenil brasileiro e algumas questões do Estatuto da Criança e do Adolescente, e da Lei 12 594/2012, que institui o Sistema Nacional de Atendimento Socioeducativo, de forma a enunciar a possibilidade de integração de práticas restaurativas no modelo no que toca a algumas medidas socioeducativas, fortalecendo-o, visando à pacificação social e a uma nova maneira de enxergar e construir a resposta aos conflitos.
\end{abstract}

PALAVRAS-CHAVE: Justiça restaurativa; Justiça juvenil; ECA; Sinase.

ABSTRACT: This study aims to briefly discuss restorative justice as a way of thinking and doing justice, restoring the role of the parties involved in the conflict. Considering the restorative movement, we will analyze some characteristics of its main restorative practices as transformative in the search for peaceful resolution of conflicts. Therefore, we will focus on the Brazilian Juvenile Justice system and some questions of the Statute of Children and Adolescents and the Law 12 594/2012, that establishes the National System of Socio-Educational Services, in order to spell out the possibility of integration of restorative practices in our model when it comes to some educational measures, strengthening it, aimed at social peace and a new way of seeing and constructing the answer to conflicts.

KEYWORDS: Restorative justice; Juvenile justice; ECA; Sinase.

\section{INTRODUÇÃOO}

Este artigo visa a uma leitura sobre o modelo de Justiça Juvenil brasileiro sob nova óptica, com base nas lentes do movimento da Justiça Restaurativa. Quando se faz referência ao modelo de justiça juvenil, se atenta para a guinada jurídica com a promulgação do Estatuto da Criança e do Adolescente (ECA) (Lei 8.069/1990) ao estabelecer a doutrina da proteção integral como orientadora do sistema da Justiça Juvenil, e seus reflexos para as políticas criminais no âmbito da adolescência.

Entrementes, se chamará atenção para a ideia de como o movimento restaurativo lançou bases e lutas para uma transformação na maneira de resposta (para) estatal da resolução de

\footnotetext{
* Doutora e mestra em Ciências Jurídico-Criminais pela Faculdade de Direito da Universidade de Coimbra; professora adjunta de Direito Penal da Faculdade de Direito da Universidade da Bahia nos cursos de graduação e pós-graduação. Promotora de Justiça (Ministério Público Militar da União). E-mail: selmadesantana@gmail.com.

** Mestrando em Direito Público pela Universidade Federal da Bahia (UFBA).

Data de recebimento do artigo: 15/01/2016 - Data de avaliação: 30/01/2016 e 08/02/2016.
} 
A justiça restaurativa como um novo olhar sobre justiça juvenil brasileira

conflitos. Em face do atual modelo de punição, a Justiça Restaurativa surge com um movimento crítico ao sistema punitivo lançando novas luzes que produzem outra visão para os fenômenos delitivos, reavendo a participação da vítima e da comunidade - quando possível - no enfrentamento das consequências advindas deste conflito. A busca de nova maneira de fazer justiça mais democrática e humana encontra resistências, de sorte que o assunto ora tratado estará na sua aplicabilidade no âmbito do sistema juvenil brasileiro por meio da análise de sua legislação.

A especialização da Justiça Juvenil surgida no Brasil é historicamente marcada por transformações ao longo do século $\mathrm{XX}$, desde a doutrina da situação irregular àquela da proteção integral. Assim sendo, a estruturação teórica da Justiça Juvenil é estabelecida em diferenciação do modelo de punição dos adultos, e, nesse aspecto, reside um liame muito intenso que contribui para ser um terreno fértil no uso das práticas restaurativas.

Com essas transformações legais na última década do século XX, atentar-se-á para a orientação jurídica do Estatuto da Criança e do Adolescente e a Lei n. 12.594/2012, que institui o Sistema Nacional de Atendimento Socioeducativo (Sinase) como objeto de pesquisa. Assim, será observado o modo como o movimento de Justiça Restaurativa, por meio de suas práticas, pode vir a ser uma nova bússola para a aplicação das medidas socioeducativas e como, por meio da Lei do Sinase, se poderá constituir uma Justiça Juvenil Restaurativa.

Discutir-se-ão as principais práticas restaurativas e quais os princípios que as norteiam, sempre visando à sua integração às medidas socioeducativas, a esclarecer a sua (in) compatibilidade de aplicação jurídica na Justiça Juvenil. Metodologicamente, se vai abordar análise legal sobre o ECA e o Sinase, lançando luz sobre a doutrina que versa o tema da Justiça Restaurativa, por meio de um exame bibliográfico nacional e estrangeiro.

Nesse ínterim, por meio de uma sucinta apresentação do Projeto-Piloto Justiça para o Século 21, que inaugura a aplicação da Justiça Restaurativa na pacificação de conflitos envolvendo crianças e adolescentes, portanto, antes mesmo da criação legal do Sinase, se poderá inferir que a Justiça Restaurativa se expressa como modelo promissor na resolução pacífica de conflitos. 


\section{JUSTIÇA RESTAURATIVA: UMA NOVA MANEIRA DE PENSAR E FAZER JUSTIÇA}

A pesquisa iniciará tratando sobre o controverso tema da Justiça Restaurativa, para depois adentrar o debate do sistema de justiça juvenil brasileiro e a possibilidade legal de aplicação de práticas restaurativas no seio das medidas socioeducativas. Será explicado o porquê de afirmar que a Justiça Restaurativa é uma nova maneira de pensar e fazer Justiça.

Quando se faz referência à expressão "Justiça Restaurativa", sua conceituação não é unânime entre seus doutrinadores. JACOOUD (2005) afirma que a Justiça Restaurativa é um modelo eclodido, diante de alguns aspectos históricos do surgimento do movimento restaurativo. Utilizaremos como marco temporal o século $\mathrm{XX}$, vez que muitos autores tendem a construir o surgimento da justiça restaurativo em práticas autocompositivas, presentes desde o início do processo civilizacional. (SANTOS, 2014).

$\mathrm{O}$ século XX representou um momento de imensa transformação social, científica, econômica, política na história da humanidade. Apesar destas transformações ainda estamos no campo do direito criminal em busca de avanços consistentes na resposta estatal aos conflitos da sociedade. No pensamento foucaultiano que analisa as relações de poder/saber, a maneira da punição, no que toca especialmente a pena de prisão, o Estado a elege como a punição mais eficaz, humanizada em comparação com o paradigma punitivo do século XVIII. FOUCAULT (1987) afirma que a própria prisão já surge em crise.

O modelo punitivo que adotamos está, dentro das teorias que justificam a pena, eivado de postulados eminentemente retributivos, dissuasórios, ressocializadores. Sua fundamentação teórica se coaduna com anseios racionalizadores da pena enquanto elemento necessário e útil na promoção da segurança da sociedade.

As teorias criminológicas passam de um modelo de estudo, antes voltado apenas na intervenção ao autor do delito, aspecto positivista, para os processos de criminalização e seletividade do sistema penal, aspecto da criminologia da reação social (SANTOS 2014). Nesse contexto, mais presente na segunda metade do século XX é que surgem os movimentos críticos ao sistema penal. Não se trata ainda de um movimento restaurativo, frise-se.

Concomitante a esta mudança nas ciências criminológicas, percebe-se o surgimento de outro movimento: a vitimologia. Os primeiros estudos ganham destaque com Heting, em 1948, todavia o olhar sobre a vítima possui um cariz positivista, onde esta é tratada como um elemento desencadeador do próprio crime. Mas a virada nesses estudos busca compreender as 
consequências que o crime resulta para a vítima, resgatando seu papel de sujeito no processo de solução do conflito em que se busca uma reparação do dano sofrido, sem que isso implique em uma diminuição dos direitos do autor. Esse movimento de descoberta da vítima, por assim dizer, é um elemento forte que implicou em mudanças na maneira de encarar a resposta criminal, especialmente no que toca a alguns de seus reflexos para a Justiça Restaurativa.

Há, ainda, o movimento abolicionista que protagoniza, até o presente momento, críticas ferrenhas ao sistema penal, seja em seus aspectos de funcionamento como na ontologia do próprio crime. Como já afirma CHRISTIE (2007), o crime não existe enquanto aquilo que se tem por força de sua própria natureza, mas é uma construção social em face de uma relatividade temporal e espacial do desvalor de certas condutas.

E nesse aspecto, o próprio sistema penal retira da vítima e das pessoas envolvidas, o conflito, o aparato judicial é o responsável por eliminá-lo e, por consequência, teremos o encarceramento como uma pena lógica (PIRES, 2005), inevitável, que causa um sofrimento não criativo, desprovido de sentido (HULSMAN, 1993). Por esse motivo, os autores deste movimento crítico concluem pela abolição do sistema penal. O Estado, aqui, punitivo, é um problema na busca pela pacificação social.

Diante desse contexto, o movimento restaurativo vai ganhando corpo e acaba por assimilar pontos destes movimentos críticos ao sistema penal. A reflexão sobre a Justiça Restaurativa é tida como complexa em meio a tantas influências, daí a alcunha de uma modelo de justiça em construção, ou, enquanto um conjunto de práticas em busca de uma teoria.

Por meio da afirmação segundo a qual a Justiça Restaurativa é um conjunto de práticas em busca de uma teoria, reside uma enorme discussão sobre os seus fundamentos históricos. Muitos autores buscam nas práticas utilizadas desde o Código de Hamurabi, Alta Idade Média, Sociedades Comunais, entre outros, como elementos que caracterizam a existência social e cultura de respostas a conflitos que podem ser considerados enquanto práticas restaurativas (SANTOS, 2014). Todavia, críticos a este modelo de análise histórica (SYLVESTER, 2003) afirmam que tais narrativas são superficiais e fazem uma releitura do passado de forma fantasiosa, um tanto quanto, mitológica.

Apesar dessas duras críticas, o que podemos observar nos autores que defendem a Justiça Restaurativa não é uma visão niilista do passado. Mas a busca por modelos utilizados pela nossa sociedade, ao longo do processo civilizacional, que possuem um grau restaurativo em detrimento do uso desmedido de penas eminentemente aflitivas. Não se estaria a buscar 
origens de um sistema de Justiça Restaurativa pronto, mas afirmar a existências de práticas de reparação. Tanto que, o autor americano HOWARD ZHER (2008) nos diz que estamos redescobrindo práticas do passado.

Esses movimentos históricos e essas leituras não esgotam por si as influências que o movimento restaurativo teve, nos limitamos apenas as estes aspectos que convergem em elementos centrais de por que a Justiça Restaurativa se enviesa enquanto um novo modelo de justiça, o qual será esclarecido no próximo tópico. No contexto do século XX é preciso pontuar fases em que as ideias restaurativas tomam corpo e acabam por influenciar politicas criminais em todo o mundo. Especialmente aqui, JACCOUD (2005) chama a atenção:

\begin{abstract}
A justiça restaurativa é, assim, o fruto de uma conjuntura complexa. Diretamente associada, em seu início, ao movimento de descriminalização, ela deu passagem ao desdobramento de numerosas experiências-piloto do sistema penal a partir da metade dos anos setenta (fase experimental), experiências que se institucionalizaram nos anos oitenta (fase de institutionalização) pela adoção de medidas legislativas específicas. A partir dos anos 90, a justiça restaurativa conhece uma fase de expansão e se vê inserida em todas as etapas do processo penal.
\end{abstract}

Após esse breve delineamento, será abordado sobre os aspectos conceituais e valorativos da Justiça Restaurativa, bem como suas principais práticas a tornam um novo modelo de pensar e fazer justiça.

\title{
1.1 Aspectos de definição da justiça restaurativa: princípios e valores
}

Pelas considerações feitas anteriormente, percebe-se claramente o contexto histórico de redescobrimento da justiça restaurativa. Foi dito, ao citar JACCOUD (2005), que este novo modelo que se apresenta, vem a ser um modelo eclodido. Para que seja estabelecida uma prática dentro da alçada da justiça restaurativa, é necessário delinear alguns requisitos para considerar aquele modelo e aquela prática como integrantes desse plexo chamado de justiça restaurativa. Segundo o autor, a Justiça Restaurativa é uma abordagem sobre o crime baseada na resolução dos problemas, que envolve às próprias partes junto à comunidade em uma relação ativa junto aos órgãos legais. (tradução nossa) ${ }^{1}$

Sua definição está orientada para aspectos particulares que resgatem uma aproximação entre vítima-ofensor-comunidade. Necessariamente, como discutido a seguir, alguns modelos não conjugam a presença simultânea desses três atores. Serão elencadas algumas posições

\footnotetext{
1 "La justice restauratrice est une approche de La délinquance baseé sur La résolution des problèmes, qui implique lesparties eles-mêmesainsi que lacommunautédans une relation active avec les organes légaux”. (MARSHALL 2011, p.149)
} 
A justiça restaurativa como um novo olhar sobre justiça juvenil brasileira

acolhidas neste trabalho em razão da diversidade dos princípios da justiça restaurativa. Seguem alguns objetivos principais da justiça restaurativa, segundo MARSHALL (2011):

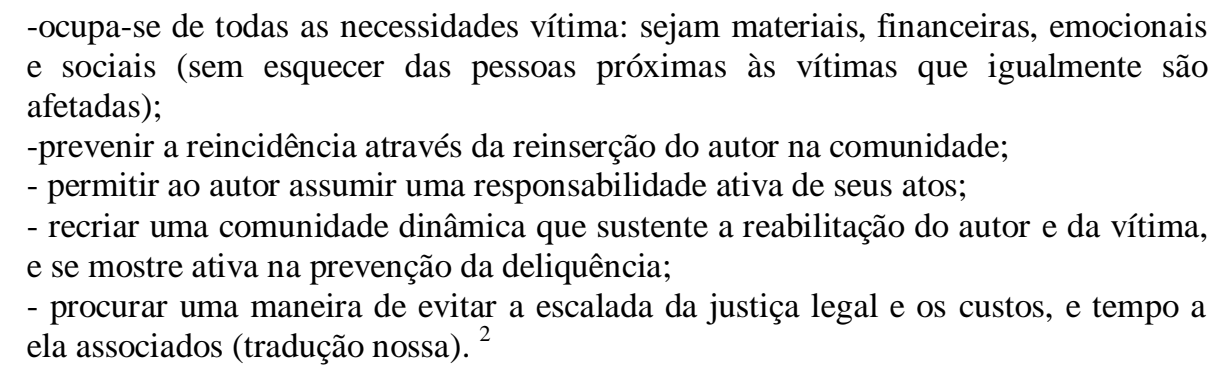

Apesar de mais genérica, essa visão dos objetivos da justiça restaurativa se assemelha com os princípios que STRONG E VAN NESS (2010) elencam:

\begin{abstract}
a) A justiça requer que trabalhemos para curar vítimas, ofensores e comunidades atingidas pelo crime;

b) Vítimas, ofensores e comunidade devem ter oportunidade de uma participação ativa no processo de justiça, tão cedo e quanto quiser;

c) Repensar os papéis e responsabilidades do governo e comunidade: na promoção da justiça o governo é responsável pela preservação de uma ordem justa e a comunidade se responsabiliza por estabelecer uma paz justa.
\end{abstract}

O cerne da justiça restaurativa estaria voltado ao amparo das vítimas (MARSHALL), mas não se resumiria apenas a esta. VAN NESS E STRONG (2010) incluem as vítimas indiretas, ou secundárias, como a comunidade, vizinhos ou familiares da vítima direta. $\mathrm{O}$ aspecto da cura revela a maneira de resposta que será tomada frente à ofensa sofrida, sendo esta rápida e que atenda as necessidades das partes envolvidas.

A oportunidade de aproximação no processo de justiça busca valorizar a participação e o envolvimento das partes. O processo penal como está estruturado, neutraliza qualquer intervenção e/ou participação de atores externos à relação jurídica penal (Estado-autor). Noutro giro, a justiça restaurativa concede poder decisivo de todos os envolvidos com a ofensa para a construção de uma resposta restaurativa aos danos sofridos e vivenciados. Para tanto, o processo de responsabilização voluntária do ofensor é um elemento importante para o início de tomada de decisões positivas, a compreensão dos danos causados e o sentido de alteridade devem ser buscados. A comunidade visará reinserir o ofensor, apoiar as vítimas e construir um consenso satisfatório que leve à reparação dos danos.

\footnotetext{
2 "s'occuper de touslesbesoin de lavictime - materiel, financier, émotionnel et social (sansoblierlesproches de lavictimquipeuventêtreégalementaffectés); prévenirlarécidivegrâce à laréisertion de l'auteurdanslacommunauté; permettre à l'auteur d'assumer une responsabilitéactive de sesactes; recréer une communautédynamiquequisoutientlaréhabilitation de l'auteur et de lavictime, et se montreactivedanslaprévetion de ladélinquance; procurer um moyen d'eviterl'escalade de la justice légale et lescoûts et délaisqui y sont associes." (Marshall, 2011, p. 150)
} 
Soma-se o papel das responsabilidades de cada ator na promoção da justiça. O Estado, amplo, busca a preservação da ordem pública. A comunidade, ao ser responsabilizada, procura promover uma paz justa. A maneira de gestão dos conflitos no seio comunitário por meio de procedimentos restaurativos deve fazer parte da promoção de uma nova maneira de encarar os conflitos.

Esses princípios servem de orientação para delinear uma maneira de pensar diferenciada em relação ao modelo retributivo de punição. É deslocar a abordagem do crime como um fenômeno abstrato, ao enxergá-lo em seus elementos interpessoais, de danos concretos, com seu sentido social e buscar uma resposta que atenda às necessidades de todos os envolvidos (ZEHR 2008).

Em relação aos valores restaurativos, a enumeração trazida por BRAITHWAITE apud PALLAMOLLA (2009) se mostra suficiente para o estudo que fazemos, embora não seja o único existente. Estes são classificados em três grupos.

Num primeiro grupo, o referido autor destaca a importância desses valores no sentido de orientação dos processos restaurativos, no respeito aos direitos humanos:

a) Não-dominação: as relações de poder estão presentes em diversas esferas do conflito, caso uma parte seja hipossuficiente a estruturação do processo restaurativo deverá minimizar essas relações de poder. O mediador deste processo terá a perspicácia de perceber o enlace de dominação e buscará dar voz aso menos favorecido;

b) Empoderamento: reflete a capacidade de superação do conflito, não-impositiva, mas de forma ativa, seja nas tomadas de decisões. É devolver o sentido de autonomia de estabelecimento das prioridades, necessidades, ou seja, retomar o "poder" de sua própria vida;

c) Obedecer aos limites de sanção impostos legalmente: por óbvio, se o processo restaurativo funciona diferentemente que o modelo tradicional retributivo, a nova sanção imposta ao fim do processo não poderá ser vexatória, ou mais dura que a cominada legalmente;

d) Escuta respeitosa: o momento de provocação do diálogo entre as partes deve promover um espaço de respeito, boa conduta. Tais requisitos são condições indispensáveis à participação e ao êxito do processo;

e) Preocupação igualitária com todos os participantes: para um bom acordo e um bom direcionamento do processo restaurativo, os anseios e necessidade de todos os envolvidos terão relevância, mesmo porque, tal processo destoa de um aplicação coercitiva que retiraria o poder de decisão das partes envolvidas; 
f) Accountability, appeability: reside na faculdade e disponibilidade que o processo penal deve oferecer ao possibilitar a opção por um processo restaurativo;

g) Respeito aos tratados de Direitos Humanos e outros textos normativos internacionais.

O segundo grupo de valores envolve a maneira de guiar o processo. É facultado aos participantes sua dispensabilidade. Essa fase está orientada por diversas maneiras de buscar a restauração, através do restabelecimento dos laços afetivos, da reparação do dano material, do amparo emocional.

O terceiro grupo de valores diz respeito ao pedido de desculpas e parte do princípio do desejo de cada um, ao proferir declarações de arrependimento voluntário e demanda ou oferta de perdão.

Todos estes elementos, que são característicos dos estudos desses autores, mostram a multiplicidade conceitual, valorativa e principiológica que cercam a justiça restaurativa. Esse novo modelo de justiça, em construção, encontra diversos sentidos. Contudo, para determinar a classificação de um determinado processo como restaurativo, a presença desses requisitos são indispensáveis, visto que, a justiça restaurativa se constrói como contraponto em relação às críticas do sistema retributivo.

Serão consideradas a seguir as principais experiências de processos restaurativos e suas principais abordagens.

\subsection{Principais modelos de práticas restaurativas}

Estabelecidos os requisitos básicos e princípios que caracterizam uma prática como restaurativa, será feita uma breve ilustração das principais experiências e modelos restaurativos, apesar da enorme gama de possibilidades concretas. Insta salientar que o momento de aplicação, não obedece a uma rígida lógica. Em verdade, é por meio da construção de experiências e programas que se estruturam determinados modelos contidos na justiça restaurativa.

Alguns processos que serão aqui rapidamente expostos se apresentam no atual sistema criminal de diversas maneiras a partir de determinadas orientações, que segundo JACCOUD (2005) apresentam a justiça restaurativa como substitutiva ao sistema punitivo, ou complementar a este: trata-se da perspectiva maximalista e a minimalista.

Sobre essas perspectivas, a autora citada sugere alguns modelos de processos que podem, ou não, serem considerados como restaurativos. O primeiro modelo consiste nos 
procedimentos voltados às finalidades restaurativas, o segundo é centrado em processos restaurativos e por último, o modelo centrado tanto nas finalidades quanto nos processos restaurativos.

O primeiro modelo de procedimentos voltados à busca de resultados restaurativos consiste na visão maximalista da justiça restaurativa. Por meio desta, buscar-se-á o resultado restauração por meios diversos e até mesmo pela obrigatoriedade do procedimento restaurativo, isto é, independentemente da aceitação das partes e gravidade do delito. Tal modelo estaria inserido no sistema judicial usando a coerção com o intuito de se alcançar um resultado restaurativo. Para LODE WALGRAVE (2011) essa perspectiva, maximalista, seria a necessária para uma transformação profunda no sistema de justiça penal.

O segundo modelo, centrado nos processos, considera que todo programa que implique participação das partes se enquadraria como restaurativo, mesmo que suas finalidades restaurativas não sejam alcançadas. Para JACCOUD (2005) este seria o modelo que mais corromperia os princípios restaurativos, pois, não bastaria apenas implementar uma justiça participativa se as ações tomadas desembocam em respostas retributivas, a exemplo de um círculo de sentenças que recomendem o encarceramento do autor do delito.

O terceiro modelo, voltado aos processos e finalidades, adota uma visão mais específica da justiça restaurativa, chamada de visão minimalista. Este se apresenta embasado nos meios de negociação e na voluntariedade; o processo restaurativo só ocorre por livre impulso das partes, todavia seu campo de atuação está restrito a pequenas infrações, o que reduz o alcance da justiça restaurativa na resolução de outros conflitos mais complexos. As críticas feitas por JACCOUD (2005) a esta visão são permeadas pela ideia de que a simples diversificação das sanções dentro do sistema estatal, incluindo o uso voluntário de processos restaurativos, mantém intacto o sistema punitivo, ainda essencialmente retributivo.

Por meio dessas abordagens de aplicação da justiça restaurativa, ao longo de século XX surgiram diversos programas que se aperfeiçoaram e estabeleceram alguns parâmetros de sua estrutura teórica e principiológica que são seguidos até os dias hodiernos. O próprio conceito de justiça restaurativa é modificado em razão de suas práticas, não constituindo uma teoria pronta sobre um novo modelo de justiça criminal. Contudo, apresenta uma forma plural e eclética de experiências bem sucedidas sobre problemas específicos sobre o crime. As práticas que contribuem com sua evolução são extremamente variadas: assistências às vítimas, mediação, conciliação, intervenção policial orientada para a resolução de conflitos, programas de reabilitação voltados pela participação comunitária. Todavia todas essas inovações 
A justiça restaurativa como um novo olhar sobre justiça juvenil brasileira

repousam no reconhecimento das necessidades de compromisso entre as partes (vítimaofensor-comunidade-órgãos judiciais). Apesar das origens diferenciadas, as novas práticas são orientadas pelos mesmos princípios de ação (participação, envolvimento da comunidade, resolução dos conflitos, flexibilidade).

O conceito da justiça restaurativa tem se aperfeiçoado. ao mesmo tempo em que suas práticas. A seguir, serão desenvolvidas três formas importantes: mediação vítima ofensor, as conferências familiares, os círculos restaurativos.

\subsubsection{A Mediação vítima ofensor}

a) A mediação vítima ofensor, surge a partir de experiências nos Estados Unidos e Reino Unido, na década de 70. O programa chamado incialmente de VORP (VictimOffenderReconciliationPrograms), como o próprio ZEHR (2008) diz, foi um campo experimental que foi se espalhando a diversos outros locais. Sua principal atuação estava orientada pela pacificação dos conflitos e pela conciliação entre as partes envolvidas.

Destaca-se neste procedimento o encontro entre vítima e autor, permitindo que ambos tenham a oportunidade de diálogo, realizar a catarse ("ventilar os sentimentos"), acompanhados por um mediador que coordenará o andamento do procedimento, prezando pela ordem e o respeito mútuo. Previamente, há o contato com a vítima e o ofensor para explicações sobre o procedimento, caso estes demonstrem interesse e voluntariamente acatem, é dada a oportunidade de realização do mesmo. O espaço de encontro será de fundamental importância para a explicação das circunstâncias do fato, a história da vítima, do autor, a quebra de estereótipos, visando a reparação do dano e, se possível, a transformação dos envolvidos. O contexto de diálogo e construção do acordo está sobre o direcionamento de assunção de responsabilidades do ofensor e sua capacidade de reparação do dano.

Este procedimento, diferentemente do processo judicial tradicional, busca empoderar os participantes para que construam uma resolução dos conflitos de forma autônoma. O mediador, em seu papel, deve ser comedido. O papel do mediador não é julgar, tampouco impor compromissos entre as partes: sua atuação deve facilitar o diálogo entre os envolvidos no conflito. Outrossim, diferentemente do distanciamento do processo judicial, a abordagem da mediação permite uma aproximação das partes, com uma finalidade transformadora positiva ao permitir a intercompreensão do conflito, um mudança de olhar sobre a situação vivenciada e sobre o outro. Nesse aspecto, a mediação buscará uma maneira de 
ressignificação conflito, por meio da alteração do sentido negativo que aquela experiência causou, levando às partes a superarem aquele episódio.

A reparação do dano não constitui uma finalidade unicamente concreta, como restituir um bem a quem sofreu um determinado dano material; a reparação se dará também no seu sentido simbólico, como um pedido de desculpas, etc. O importante é a compreensão de que o dano causou um mal a alguém e buscar uma maneira de repará-lo.

Quando se fala em mediação, geralmente pensamos na participação obrigatória da vítima e do ofensor. Essa prática restaurativa poderá ter outras modalidades e outras nomenclaturas em razão do espaço onde ela ocorre e em razão da participação das partes. Assim temos a possibilidade da mediação escolar, mediação comunitária, mediação indireta. Estruturalmente, essas formas de realizar a mediação possuem as mesmas bases, excetuandose a mediação indireta onde não há o contato direto entre vítima e ofensor.

Uma diferenciação entre estas modalidades está no seu momento de aplicação. A mediação pode acontecer em espaços diversos, sejam institucionalizados ou não. No caso da mediação escolar e comunitária, o conflito mediado não está sob o controle do sistema de justiça criminal. Já em casos que envolvam processos judiciais, a mediação poderá ser utilizada antes da sentença como mecanismo de busca pelo acordo entre as partes, e influenciando a própria decisão do juiz.

\subsubsection{Conferencing}

As conferências familiares (Conferencing), segundo VAN NESS E STRONG (2010), são também conhecidos como câmaras restaurativas. Este modelo foi inspirado nas observações do povo Maori que são indígenas da Nova Zelândia.

Há dois modelos básicos de interferência que este procedimento causará na resolução dos conflitos, refletindo no momento de sua aplicação: na primeira forma os casos (sempre que possível) não são levados para o sistema de justiça (modelo neerlandês), na segunda a polícia ou a escola facilitam o encontro entre as partes e os familiares (JACCOUD, 2005).

Os participantes destas conferências são a vítima, o ofensor, seus familiares, os representantes das autoridades, e a comunidade. Diferentemente da mediação autor-vítima, o terceiro, que interfere nesse procedimento, é chamado de facilitador. Este visa a facilitar a comunicação em razão do mero resultado (busca pelo acordo). 
A justiça restaurativa como um novo olhar sobre justiça juvenil brasileira

As conferências familiares possuem uma estrutura simples com algumas etapas: inicialmente o facilitador explica como ocorrerá a conferência, suas regras e a necessidade do respeito aos momentos de fala e escuta. Em seguida, o espaço é aberto para a realização dos diálogos com o momento de o ofensor narrar seus fatos, depois os presentes discutem sua visão sobre o ocorrido e sugerem algumas perguntas ao ofensor e à vítima.

Superado o momento de discussões sobre o conflito, pretende-se chegar a um consenso sobre um plano de ação para reparação do dano, onde o ofensor se compromete a cumprir o acordo estabelecido. A relevância deste procedimento está justamente na influência positiva que as pessoas mais próximas do círculo social do ofensor geram, constituindo uma espécie de controle social familiar. O ofensor, por conseguinte, buscará não apenas cumprir o acordo, mas também não decepcionar as pessoas mais próximas dele que participaram deste procedimento.

\subsubsection{Círculos Restaurativos}

Os círculos restaurativos consistem em reuniões participativas, que visam a integração de várias pessoas afetadas pelo conflito com o intuito de resolvê-lo de modo respeitoso. Apesar de outras nomenclaturas como círculos de cura ou grupos focais os encontros buscam a superação dos traumas sofridos por meio da exposição dos sentimentos e construção de novos sentidos. Aqui também há a presença do facilitador que desempenhará a mesma atribuição descrita anteriormente.

Existem também na linha dos círculos restaurativos, os círculos de sentença, cujo propósito é estabelecer indicações para o juiz aplicar medidas restaurativas ao ofensor. Seu uso será feito, logicamente, antes da decisão do juiz.

A realização dos círculos restaurativos poderá ser feita em diversos momentos: antes do processo judicial, antes da prolação da sentença ou ainda, após a sentença. Sua ideia básica consiste no envolvimento da comunidade para a resolução dos conflitos; quanto maior for a amplitude de participação, melhor para o procedimento. Note-se que tal prática restaurativa é recente, razão pela qual não se possui ainda muitos estudos a seu respeito (ZEHR, 2008).

Importa dizer que não esgotamos todos os aspectos teóricos da Justiça Restaurativa, bem como os meandros de todas as suas práticas, tivemos uma visão panorâmica sobre esse tema. Após essa breve análise sobre a Justiça Restaurativa e algumas de suas práticas, será discutido, com base numa análise legal, o modelo de Justiça Juvenil Brasileiro e como o 
movimento restaurativo possui espaço para o desenvolvimento de práticas nesse sistema de justiça.

\section{JUSTIÇA JUVENIL BRASILEIRA}

Este tópico analisa alguns pontos sobre a Justiça Juvenil Brasileira com base na reflexão trazida no texto de Álvaro Pires (2006), "Responsabilizar ou punir? A justiça juvenil em perigo". Por meio de suas reflexões sobre alguns deslocamentos cognitivos de sistematização da justiça juvenil, será abordado um breve olhar sobre a maneira de estruturação teórica da justiça juvenil, além de mencionarmos a mudança estabelecida com a doutrina da proteção integral na justiça juvenil brasileira.

O tratamento dos jovens infratores frente ao estado brasileiro se modificou ao longo do século XX. Antes do primeiro código de menores (1927), não havia distinção de tratamento entre jovens e adultos, consolidou-se em uma segunda etapa, de 1927 até o código de 1979, a visão da tutela dos jovens em situação regular. Aqui, o "de menor" alcunha pejorativa muito utilizada, era encarado não como um sujeito de direitos, mas objeto de intervenção do estado com o fulcro de recuperá-lo do meio danoso em que estava imerso. Frequentes eram as internações, como os locais de "acolhimento" desses menores (SPOSATO, 2011).

Com a promulgação da Constituição de 1988, o Brasil insere a doutrina da proteção integral em seus artigos 227 e 228. Nestes, é dever de todos, não apenas da família, assegurar direitos básicos à sua condição de ser humano em desenvolvimento. Por esse pressuposto, a estruturação do sistema de proteção da criança e do adolescente modifica-se radicalmente em relação ao antigo paradigma da situação regular. Com a cristalização da lei 8.069/1990, o ECA, constitui-se uma das legislações de menores mais avançadas do mundo, juntamente com o impulso de normas internacionais como o acolhimento de princípios da Convenção sobre os Direitos Criança em 1989.

Algumas características serão necessárias como ponto de reflexão e partem sobre o modo como as normas legais do estado brasileiro encaram o jovem infrator.

No estudo de PIRES (2009), uma diferença marcante na forma de encarar o menor delinquente reside no fato de enxergá-lo como "uma parte inseparável do todo (sociedade). Ele permanece um membro por inteiro do grupo e deve se tratado como tal" (PIRES, 2009). Por esta premissa, a justiça juvenil é balizada, dessa forma, na atuação sobre o menor delinquente que buscará o afastamento dos princípios retributivos da justiça dos adultos. 
A justiça restaurativa como um novo olhar sobre justiça juvenil brasileira

Haverá um distanciamento cognitivo, organizacional que se consolida em meados do século XX, a exemplo das instituições de reclusão diferenciadas, separação das audiências, não estigmatização e publicização de casos envolvendo menores, juízo próprio para os julgamentos de seus casos. Essa última característica se baseia na tentativa de distanciamento da forma de pensar dos juízes, dissociando a maneira de pensar a justiça dos adultos com a dos jovens.

O ordenamento brasileiro albergou essas características de especialização da justiça juvenil. A finalidade da aplicação da medida socioeducativa, esta excepcional, reside também em princípios restaurativos que serão posteriormente aprofundados, quais sejam a responsabilização, integração social do adolescente, prioridade no uso de práticas restaurativas. Logo, a abertura cognitiva está posta e, pela primeira vez, exposta em um documento legal dentro do ordenamento jurídico brasileiro.

Por seu turno, a doutrina da proteção integral se apresenta, inicialmente, como a abertura cognitiva que necessitávamos, para pensar a justiça juvenil afastada dos postulados básicos da justiça dos adultos retributiva. Esse primeiro passo que o ordenamento jurídico brasileiro acolhe tornará fértil a aproximação que aqui faremos da justiça juvenil com a justiça restaurativa.

No dizer de Antônio Carlos Gomes da Costa, a Doutrina da Proteção Integral:

[...] afirma o valor intrínseco da criança com ser humano; a necessidade especial de respeito à sua condição de pessoa em desenvolvimento; o valor prospectivo da infância e da juventude como portadora da continuidade do seu povo e da espécie e o reconhecimento de sua vulnerabilidade. O que torna as crianças e adolescentes merecedores de proteção integral por parte da família, da sociedade, do Estado, o qual deverá atuar através de políticas específicas para promoção e defesa de seus direitos (COSTA, 1992)

Nesta senda, o tratamento dado pelo Estatuto da Criança e do Adolescente funda-se sobre três premissas básicas: liberdade, respeito e dignidade. Essa perspectiva protetiva desloca o antigo contexto de tutela normativa dispensado apenas ao Estado, ao coisificar os jovens em situação irregular, ou ainda, trata-los como adultos em miniatura, sobre a égide suprema da Política Nacional de Bem-Estar do Menor, tratado como assunto de segurança nacional pela ditadura militar brasileira.

Após essa guinada da doutrina da situação irregular, para a da proteção integral, mudase a forma de o estado encarar a aplicação das medidas socioeducativas. Estas, não terão a mensagem de reprovação da conduta infracional de cunho retributivo, ter-se-á, por seu turno, a finalidade socioeducativa. Mesmo porque, como o próprio ECA estabelece: a regra será a 
primazia pelo direito à liberdade do jovem infrator (art. 107, § único) juntamente como princípio da excepcionalidade da medida de internação (art. 121). O giro cognitivo entre a doutrina da situação irregular, para a proteção integral, trouxe consigo um novo entendimento, uma nova maneira de encarar os adolescentes infratores como seres em desenvolvimento, a quem deve ser garantido um núcleo de direitos fundamentais. Por esta razão, àqueles que estejam em desacordo com a lei não serão considerados inimigos públicos, mas sujeitos que necessitam do amparo do Estado, da família e da sociedade.

A mudança nessa política criminal voltada aos adolescentes e os atos infracionais possui uma mudança cristalizada com o estabelecimento do Sistema Nacional de Atendimento Socioeducativo a partir da Lei 12.594/2012. A seguir, será abordado como esse texto normativo é terreno fértil para que a Justiça Restaurativa seja implementada no seio da Justiça Juvenil Brasileira.

\subsection{A justiça restaurativa e o Sistema Nacional de Atendimento Socioeducativo}

A aproximação que o Estatuto da Criança e do Adolescente trouxe para o Brasil no que se refere a princípios restaurativos consagra-se, mesmo que tardiamente, com a Lei 12.594/2012 do Sistema Nacional de Atendimento Socioeducativo (Sinase). A promulgação desta resultou na afirmação principiológicado ECA, qual seja, o compromisso pelo respeito ao adolescente infrator e a busca por uma justiça digna.

Isso significa dizer que, se compararmos o antigo paradigma de tratamento legislativo dispensado ao "menor", com a transição para a doutrina da proteção integral e a cristalização de novos institutos e principiologias do direito da criança e do adolescente, se está ante uma tentativa do estado de agir positivamente diante do adolescente infrator. Busca-se uma superação das antigas concepções autoritárias de defesa social e aplicação de medidas retributivas.

O próprio ECA estabelece que a interferência a ser feita no adolescente em conflito com a lei é realizada com um processo pedagógico que possibilite e torne excepcional o abuso da internação (restrição de liberdade), em razão do fortalecimento efetivo do convívio familiar e comunitário, da educação para a vida social

Apesar das aberturas legislativas do ECA permitissem a valoração de práticas restaurativas, somente explicita-se essa direção quando da aplicação das medidas socioeducativas do art. 112 do ECA, orientadas pela lei do SINASE. É clarividente a 
inclinação dos pressupostos básicos da justiça restaurativa quando da execução das medidas socioeducativas sendo esta: a aproximação entre vítima e autor da infração, escuta da vítima, possibilidade da autocomposição dos conflitos, reparação do dano.

Observa-se, ainda, que o procedimento de responsabilização do jovem é fato presente. As finalidades da aplicação das medidas socioeducativas se colocam em um plano diferenciado do que ocorre na justiça dos adultos, exclui-se o plano da retribuição em detrimento da reparação, conforme dispositivos normativos:

Art. $1^{\mathrm{o}}, \S 2 \mathrm{o}-$ Entendem-se por medidas socioeducativas as previstas no art. 112 da Lei n. 8.069, de 13 de julho de 1990 (Estatuto da Criança e do Adolescente), as quais têm por objetivos:

I - a responsabilização do adolescente quanto às consequências lesivas do ato infracional, sempre que possível incentivando a sua reparação;

II - a integração social do adolescente e a garantia de seus direitos individuais e sociais, por meio do cumprimento de seu plano individual de atendimento; e

III - a desaprovação da conduta infracional, efetivando as disposições da sentença como parâmetro máximo de privação de liberdade ou restrição de direitos, observados os limites previstos em lei.

A principiologia do Sinase se aplica a todas as medidas socioeducativas, contudo, no objeto de estudo dessa pesquisa nos atemos apenas às medidas socioeducativas que não importem a restrição de liberdade do jovem infrator.

Noutro sentido, importa salientar o que reza o art. 35 da referida lei:

Art. 35. A execução das medidas socioeducativas reger-se-á pelos seguintes princípios:

I - legalidade, não podendo o adolescente receber tratamento mais gravoso do que o conferido ao adulto;

II - excepcionalidade da intervenção judicial e da imposição de medidas, favorecendo-se meios de autocomposição de conflitos;

III - prioridade a práticas ou medidas que sejam restaurativas e, sempre que possível, atendam às necessidades das vítimas; (grifo nosso).

No rol taxativo das medidas socioeducativas elencadas no art. 112 do ECA, podemos nos referir à prestação de serviços comunitários, que entrará em fase executória. $\mathrm{O}$ delineamento de programas restaurativos nessa fase do processo partirá de uma predisposição institucional. Juntamente com o Plano Individual de Acompanhamento (PIA) previsto no art. 52, ter-se-á outra abertura legislativa que facilmente alberga, os usos de procedimentos restaurativos, cumprindo os objetivos e princípios das medidas socioeducativas, previstos nos arts. $1^{\circ}$ e $35^{\circ}$ da Lei federal 12.594/2012.

O Direito da Criança e do Adolescente no Brasil possui direcionamentos avançados no plano teórico no que se refere à viabilidade da justiça restaurativa, a feliz aproximação da 
justiça juvenil brasileira busca um rompimento com o tratamento anteriormente dado ao jovem infrator. Esse novo paradigma posto não seria possível sem a abertura legislativa trazida tanto pelo ECA, quanto pelo SINASE.

Após essa rápida abordagem sobre o SINASE iremos, no próximo tópico, verificar alguns aspectos legais e procedimentais que incluem o uso de práticas restaurativas nos e seus momentos de aplicação, ao considerarmos apenas as medidas socioeducativas que não impliquem na internação do adolescente infrator.

\subsection{Práticas restaurativas e medidas socioeducativas: correlação possível}

É claramente possível a implementação de práticas restaurativas na justiça juvenil, sem que implique numa mudança legislativa. Neste momento, com base no próprio ECA, será feita uma análise das medidas socioeducativas em que será possível a aplicação de procedimentos restaurativos. Seguem as medidas socioeducativas:

\footnotetext{
Art. 112. Verificada a prática de ato infracional, a autoridade competente poderá aplicar ao adolescente as seguintes medidas:

I - advertência;

II - obrigação de reparar o dano;

III - prestação de serviços à comunidade;

IV - liberdade assistida;

$\mathrm{V}$ - inserção em regime de semi-liberdade;

VI - internação em estabelecimento educacional;

VII - qualquer uma das previstas no art. 101, I a VI.

$\S 1^{\circ}$ A medida aplicada ao adolescente levará em conta a sua capacidade de cumprila, as circunstâncias e a gravidade da infração.

$\S 2^{\circ}$ Em hipótese alguma e sob pretexto algum, será admitida a prestação de trabalho forçado.

$\S 3^{\circ}$ Os adolescentes portadores de doença ou deficiência mental receberão tratamento individual e especializado, em local adequado às suas condições.
}

Art. 113. Aplica-se a este Capítulo o disposto nos arts. 99 e 100.

A estruturação legislativa das medidas socioeducativas caminha para um critério de gradação, partindo da medida mais leve, para uma mais grave. A advertência é a medida mais leve, aplicada pelo juiz em audiência com a presença dos pais do jovem infrator. Inserir neste momento alguma prática restaurativa é possível. O "puxão de orelha" dado não faria muito sentido se o jovem não compreender o sentido negativo que seu ato provocou. Acompanharse-ia a esta medida uma composição de conflito com a vítima de modo ao jovem firmar 
A justiça restaurativa como um novo olhar sobre justiça juvenil brasileira

judicialmente uma retratação, um pedido de desculpas. Vimos, anteriormente, que a reparação possui um lado simbólico, e seria aplicável neste caso.

A segunda medida, a obrigação de reparar o dano é aplicável quando o ato praticado implica em danos patrimoniais à vítima. Essa, logicamente, será substituível quando a reparação não for possível, nos termos do parágrafo único do artigo 116 do ECA. Outra questão levantada quando da aplicação da medida será a capacidade de o jovem infrator cumpri-la.

Reparar o dano, como já debatido, constitui-se em uma das finalidades da justiça restaurativa. O caminho trilhado para que haja a restauração perpassa na participação da comunidade, da própria vítima e os envolvidos com o conflito. No contexto da justiça juvenil isso é claramente possível, vez que, o art 100 do ECA preleciona o uso de medidas que fortaleçam os laços comunitários e familiares. Enquadra-se, para tanto, no modelo teórico da justiça restaurativa.

A atenção que será dispensada à vítima se coaduna com a finalidade de resgate de sua opinião e sentimentos sobre o ocorrido e a maneira de repará-la. Em casos que envolvem danos patrimoniais, para além das responsabilidades civis que os pais possuem frente aos atos de seus filhos, no caso desta medida socioeducativa, se se busca a finalidade restaurativa quando o próprio jovem infrator reparar o dano.

Outra medida, a prestação de serviços à comunidade está dentro da linha restaurativa. Previsto no artigo 117 do ECA, o jovem infrator realizará tarefas gratuitas e de interesse geral (comunitário). Desse modo, como já restou demonstrado, a participação da comunidade próxima ao jovem infrator amplia o rol de efetividade da justiça juvenil, que se diferencia do puro retribucionismo. $\mathrm{O}$ ato infracional não afeta apenas a vítima direta, a comunidade se insere no contexto como vítima indireta e, por seu turno, deverá fazer parte da construção do acordo restaurativo.

Importa ressaltar, a preocupação que a justiça restaurativa guarda em coletivizar a gestão do conflito, de modo a integrar diversos atores envolvidos na busca de uma solução justa e possível. Ao trazermos essa diretriz para a justiça juvenil não estamos inovando, apenas trazendo á lume o que está no próprio Estatuto da Criança e do Adolescente, e ainda, nas orientações do próprio Sistema Nacional de Atendimento Socieducativo.

Essa medida, prestação de serviços comunitários, será bem vinda quando visar à integração do adolescente infrator à comunidade afetada, derrubando rótulos e aprofundando 
laços. Seu empenho será crucial para demonstrar responsabilidades sobre seus atos e reconhecimento das normas de convivência.

Adentraremos, agora, no mérito da liberdade assistida. Essa medida, de grau mais enérgico, estabelece o acompanhamento em meio aberto dos jovens infratores. Possui prazo mínimo de seis meses e caracteriza-se pela presença de um orientador. A execução dessa medida, além de observar o disposto no Sinase possui, também, a possibilidade de aplicação de práticas restaurativas. Nesta, o orientador deverá interagir com os familiares, comunidade envolvida com o conflito, para estabelecer, negociadamente, a melhor gestão do conflito. $\mathrm{O}$ Estatuto indica a participação em alguns programas comunitários, acompanhamento do desempenho escolar. Contudo, para além do estabelecido, é notadamente possível o uso de círculos restaurativos para a produção do relatório requisitado no art.119, IV e avaliação do comportamento do jovem infrator.

A viabilidade do uso de práticas restaurativas, como resta demonstrado é possível. Mas chamamos atenção para um dado nacional que é alarmante e se distancia da essência restaurativa que discutimos como possível na justiça juvenil: o Brasil possui uma alta taxa de internação de adolescentes infratores. Isso revela uma realidade assustadora e que destoa da finalidade restaurativa que o Sinase e o ECA sinalizam para a resolução das condutas infracionais.

\section{JUSTIÇA PARA O SÉCULO XXI: BREVES COMENTÁRIOS}

O que se afirmou consiste no fato de a Justiça Restaurativa ser sim um modelo presente no sistema de Justiça Juvenil, de forma a agir harmonicamente com os preceitos legais na seara normativa juvenil, revalorizando o aspecto do conflito e cumprindo um papel transformador. Dessa maneira, percebemos que a realidade não deve destoar daquilo que a norma prevê, assim abordamos a título exemplificativo o programa implementado, experimentalmente no Brasil, Justiça para o Século 21.

No "Projeto Justiça para o Século 21" criado em parceria com o Ministério da Justiça e o Programa das Nações Unidas para o Desenvolvimento (PNUD) em 2005 é aplicado na $3^{\text {a }}$ Vara Regional do Juizado da Infância e da Juventude de Porto Alegre. Seu objetivo, genericamente é o de implementar as práticas da Justiça Restaurativa na pacificação de situações de violência envolvendo crianças e adolescentes em Porto Alegre. Sua maneira de atuação constitui uma complementação ao sistema de justiça tradicional, inserindo 
A justiça restaurativa como um novo olhar sobre justiça juvenil brasileira

procedimentos restaurativos no âmbito dos processos judiciais de execução de medidas socioeducativas e programas de atendimentos socioeducativo (PALLAMOLLA, 2009). Segundo próprio trabalho publicado sobre o projeto em comento, estabelece-se a justificativa de aplicação das medidas restaurativas nessa fase, pela seguinte maneira:

\begin{abstract}
Considera-se que a riqueza desta particular aplicação está exatamente em transformar em restaurativo aquilo que está sólida e inegavelmente instalado numa (des) funcionalidade retributiva, com discurso terapêutico nas práticas convencionais do Sistema de Justiça e de Atendimento Socioeducativo. A Justiça Restaurativa tem sido acolhida na experiência de Porto Alegre justamente como eixo estruturante e ordenador das concepções disfuncionais do sistema de execuções socioeducativas, buscando reduzir o dano de violência cultural, institucional e historicamente instaladas nas formas usuais de responsabilização penal dos adolescentes submetidos à jurisdição socioeducativo. (BRANCHER, AGUINSKY, 2008)
\end{abstract}

De tal forma, percebe-se a intenção básica estabelecida: realizar o uso de práticas restaurativas, na execução das medidas com uma quebra, ou melhor, um instrumento de transformação sobre a ótica (novas lentes) de aplicação das medidas. Significa alcançar uma mudança de valores e práticas institucionais.

Não serão aprofundadas as políticas adotas por este projeto, vez que o intento fora alcançado nos tópicos anteriores, no sentido de compreender que o funcionamento da Justiça Juvenil permite, do ponto de vista legal, albergar o uso de práticas restaurativas. E esta conclusão pode ser evidenciada nos projetos utilizados no Brasil. Resta ao Estado se utilizar dessas experiências de modo mais amplo, enquanto uma política nacional no âmbito da resolução de conflitos.

Essa transformação é possível porque a Justiça Restaurativa em si possibilita a afirmação do sistema de justiça juvenil enquanto um modelo de resposta aos atos infracionais diferente. No sentido de que não se tratar o adolescente em conflito com a lei enquanto um inimigo público, equiparado a estigma do sistema penal dos adultos. O que se busca afirmar é que o sentido de incorporação das práticas restaurativas pela Justiça Juvenil possibilita seu aperfeiçoamento e sua afirmação enquanto um modelo de justiça mais humano.

O curioso reside no nome do projeto (Projeto Justiça para o Século 21) que carrega em si a noção de transformação na maneira de pensar e fazer justiça, sempre com o intuito de melhorá-la. Coaduna-se, portanto, com a visão diferenciada da Justiça Restaurativa, que resgata a participação da vítima no processo, a busca pela satisfação dos envolvidos no processo, a resolução do conflito de forma a atender os anseios psicológicos e simbólicos das partes, visando a alteridade, respeito, emancipação. Responder a uma situação de conflito de 
forma diferenciada, afastando a resposta essencialmente punitiva é o cerne que amplia as discussões para o estabelecimento do movimento restaurativo.

\section{CONCLUSÃO}

Por todo o expresso, não se usa exprimir a ideia de que esta discussão termina; muito pelo contrário. O tema que versa sobre a Justiça Restaurativa é demasiado amplo, e aqui se procedeu a um pequeno recorte no que toca na análise de alguns elementos desse modelo de justiça integrado ao sistema de Justiça Juvenil brasileiro. $\mathrm{O}$ intuito do artigo foi demonstrar a necessidade de se debater e ampliar a aplicação da Justiça Restaurativa, a fornecer uma nova lente para se enxergar as respostas aos conflitos, ocorrendo de forma autocompositiva e pacífica.

Iniciou-se o debate sobre o contexto de (res) surgimento das práticas restaurativas e as críticas ao modelo de Justiça Penal, essencialmente retributivo. Foram reunidos alguns princípios que norteiam a caracterização de práticas restaurativas, sempre visando à reparação do dano, seja ela material ou simbólica. Exprime-se a necessidade de resgate do conflito para que as partes envolvidas direta ou indiretamente, realizem uma transformação positiva; e tal desemboca na elaboração de uma nova forma de pensar a justiça.

Frise-se a noção de que a Justiça Restaurativa não surge como um modelo que resolveria todos os problemas envolvidos na questão criminal. Esta se propõe a indicar outra visão sobre o conflito. Demanda-se uma nova racionalidade de respostas para a complexidade envolvida no fenômeno delitivo, dispensando a carga negativa de retribuição em decorrência do estabelecimento de soluções para as consequências ocorridas.

Integrado a essas ideias do movimento restaurativo, compreende-se como o sistema de Justiça Juvenil é terreno fértil para o uso das práticas restaurativas, seguindo a orientação tratada pelo Sinase. Desse modo, não existe incompatibilidade legal, formal que obste o uso das práticas restaurativas no seio da Justiça Juvenil. O que corrobora essa ideia está no Projeto Justiça pra o Século XXI, sucintamente apresentado, como um modelo que deve ser difundido em todo o País, para que seja possível exercer uma posição transformadora na maneira de fazer e pensar a Justiça.

Álvaro Pires (2009) chamava a atenção para o movimento de endurecimento de normas que aproximariam o sistema de Justiça Juvenil ao sistema penal dos adultos, havendo uma espécie de colonização daquele por este. Infelizmente, são vivenciados movimentos 
nesse sentido, especialmente agora quando o Parlamento brasileiro ensaia a redução da maioridade penal, e os debates conservadores avançam. $\mathrm{O}$ ponto-chave descansa em se utilizar as boas práticas no sistema juvenil e aperfeiçoá-las com o modelo restaurativo no intuito de fortalecer a Justiça Juvenil, a fazer com que ela se firme como modelo de resposta distinto do sistema penal dos adultos, não apenas em sua perspectiva teórica, bem como em suas práticas. Só assim, será consolidada uma transformação na maneira de pensar a justiça.

\section{REFERÊNCIAS}

AGUINSKY, Beatriz Gershenson; BRANCHER, Leoberto Narciso. Relato da implementação do Projeto-Piloto de Justiça Restaurativa junto à $3^{\text {a }}$ Vara da Infância e da Juventude de Porto Alegre, RS, visando à introdução de práticas restaurativas na pacificação de situações de violências envolvendo crianças e adolescentes. 2008. Disponível em:<http\%3A\%2F\%2Fwww.justica21.org.br\%2Farquivos\%2Fbib_241.doc\&ei=miadUo_pH _HjsASNx4Fg\&usg=AFQjCNGujAP6VbceqWhPEbFhr6sQdAYRQ\&bvm=bv.57155469,d.cWc>. Acesso em 04 de jul de 2015.

BRASIL. Constituição (1998). Constituição da República Federativa do Brasil de 05 de outubro de 1988. Diário Oficial [da] União, Poder Legislativo, Brasília, n. 191-A, 05 de out. 1988.

BRASIL. Lei n ${ }^{\circ}$ 8.069, de 13 de julho de 1990. Dispõe sobre o Estatuto da Criança e do Adolescente e dá outras providências. Diário Oficial [da] União, Poder Executivo, Brasília, DF, 16 jul. 1990.

Lei $\mathbf{n}^{0} 12$ 594/12. Institui o Sistema Nacional de Atendimento Socieducativo. Senado Federal, Brasília 2012.

CHRISTIE, Nils. Limits to pain, The Role of Punishment in Penal Policy, Eugene: Wipf and Stock Publishers, 2007 ( $1^{\mathrm{a}}$ ed. de 1981)

COSTA. Antônio Carlos Gomes da. Natureza e implantação do novo Direito da Criança e do Adolescente. In: PEREIRA, Tânia da Silva (coord). Estatuto da Criança e do Adolescente: Lei 8.069/90: estudos sócios-jurídicos. Rio de Janeiro: Renovar, 1992.

FOUCAULT, Michel. Vigiar e punir: História da violência nas prisões. Petrópolis: Vozes, 1987. 
HULSMAN, Louk; CELIS, Jaqueline B. de. Penas perdidas. O sistema penal em questão, Niterói: Luam Editora, 1993.

JACCOUD, Mylène. Princípios, Tendências e Procedimentos que cercam a Justiça Restaurativa. In: SLAKMON, Catherine; DE VITTO, Renato Campos Pinto; GOMES PINTO, Renato Sócrates (org.). Justiça restaurativa. Brasilia/DF: Ministério da Justiça e PNDU, 2005, p. 163-188.

MARSHALL. Tony F. La Justice Restauratrice: vued'ensemble. In: Gaily, Philippe (org). La Justice Restauratrice. Bruxelles: Larcier, 2011.

PALLAMOLLA, Rafaella da Porciuncula. Justiça Restaurativa: da teoria à prática. São Paulo: IBCCRIM, 2000.

PIRES, Álvaro. Responsabilizar ou punir? A justiça juvenil em perigo. In Novas direções na governança da Justiça e Da Segurança. Slakmon, Catherine;et. al. (orgs.). Brasília-DF: Ministério da Justiça, 2006.

SANTOS, Cláudia Cruz. A Justiça Restaurativa. Um modelo de reacção ao crime diferente da Justiça Penal. Porquê, para quê e como? Coimbra: Coimbra Editora, 2014

SCURO NETO, Pedro. A Justiça Como Fator de Transformação De Conflitos: Princípios E Implementação. Contribuição ao Simpósio Internacional da Iniciativa Privada para a Prevenção da Criminalidade. NEST/Câmara de Comércio e Indústria Brasil-Alemanha, São Paulo, abril de 2000. Disponível em: <http://www.restorativejustice.org/10fulltext/scuro2> Acessado em 15 de junho de 2015.

SPOSATO, Karyna Batista Elementos para uma teoria da responsabilidade penal de adolescentes. 227 f. Tese (Doutorado) - Universidade Federal da Bahia Faculdade de Direito, 2011. Orientadora: Profa. Dra. Maria Auxiliadora Minahim.

SYLVESTER, Douglas, Myth in Restourative Justice History, Utah Law Review, 2003, nº 1 , pag 471-522.

VAN NESS, Daniel; STRONG, Karen. Restoring justice: an introduction to restorative justice.LexisNexisGroup, Cincinnati, 2010.

WALGRAVE, Lode. Comment convier Justice Restauratice et Justice Pénale: questios et discussions. In: Gaily, Philippe (org). La Justice Restauratrice. Bruxelles: Larcier, 2011.

ZEHR, Howard. Trocando as lentes: um novo foco sobre o crime e a justiça. São Paulo: Pala Athena, 2008.

Justice Rétributive, Justice Restauratrice. In: Gaily, Philippe (org). La Justice Restauratrice. Bruxelles: Larcier, 2011. 